\title{
A Case of Recurrent Thrombotic Microangiopathy Caused by Hypertensive Urgency
}

\author{
Farman Ali ${ }^{1}$, Aman Ullah ${ }^{2}$, Waseem Amjad ${ }^{3}$, Tanureet Kochar ${ }^{4}$, Frank H. Annie ${ }^{5}$, Ali Farooq ${ }^{4}$
}

1. Medicine, St. John Hospital and Medical Center, Detroit, USA 2. Internal Medicine, St. Joseph Mercy Oakland Hospital, Pontiac, USA 3. Digestive Diseases, Mercy Medical Center, Baltimore, USA 4. Internal Medicine, West Virginia University/Charleston Area Medical Center, Charleston, USA 5. Cardiology, West Virginia University/Charleston Area Medical Center, Charleston, USA

Corresponding author: Ali Farooq, dr.aliumair786@gmail.com

\begin{abstract}
A 26-year-old man presented to the emergency room with abdominal pain, nausea, and vomiting for four days. His medical history was significant for hypertension and end-stage renal disease managed with hemodialysis. He had been noncompliant with the antihypertensive regimen which included nifedipine, hydralazine, and spironolactone. At presentation, his blood pressure was $231 / 123 \mathrm{mmHg}$. Laboratory workup showed white blood count $17.3 \times 109 / \mathrm{L}$ (normal range: 4.5 to $11.0 \times 109 / \mathrm{L}$ ), hemoglobin $7.8 \mathrm{gm} / \mathrm{dL}$ (normal range: 13.5 to $17.5 \mathrm{~g} / \mathrm{dL}$ ), platelet count $46 \times 109 / \mathrm{L}$ (normal range: 150 to $400 \times 109 / \mathrm{L}$ ), reticulocyte count $7.8 \%$, total bilirubin $1 \mathrm{mg} / \mathrm{dL}$ (normal range: 0.1 to $1.2 \mathrm{mg} / \mathrm{dL}$ ), lactate dehydrogenase $1,235 \mathrm{U} / \mathrm{L}$ (normal range: 140 to $280 \mathrm{U} / \mathrm{L}$ ), haptoglobin < $10 \mathrm{mg} / \mathrm{dL}$, and a direct Coomb's test was negative. Numerous schistocytes were identified on the peripheral blood smear. The patient was diagnosed with thrombotic microangiopathy secondary to severe hypertension and was started on intravenous nicardipine. With appropriate blood pressure control, hematological parameters improved with normalization of the platelet count within 10 days. Notably, the patient had one similar episode of hypertension-induced thrombotic microangiopathy within a period of the last three months and ADAMTS-13 (a disintegrin and metalloprotease with thrombospondin type 1 motif 13 ) activity was normal on his previous admission.
\end{abstract}

Categories: Cardiology, Internal Medicine, Other

Keywords: thrombotic microangiopathy, hypertensive urgency, thrombotic thrombocytopenic purpura

\section{Introduction}

Thrombotic microangiopathy (TMA) is a clinical syndrome that is characterized by microangiopathic hemolytic anemia, thrombocytopenia, and end-organ damage [1].

Several causes of TMA have been described, including thrombotic thrombocytopenic purpura (TTP), hemolytic uremic syndrome, malignancy, drugs, and severe hypertension. The threshold of blood pressure

Received 03/27/2018

Review began 08/14/2018 Review ended 08/19/2018 Published 08/30/2018

\section{() Copyright 2018}

Ali et al. This is an open access article distributed under the terms of the Creative Commons Attribution License CC-BY 3.0., which permits unrestricted use, distribution, and reproduction in any medium, provided the original author and source are credited. beyond which TMA occurs remains unknown; however, TMA appears to occur more frequently when systolic and/or diastolic blood pressures exceed $200 \mathrm{mmHg}$ and $100 \mathrm{~mm} \mathrm{Hg}$, respectively [2]. The initial clinical presentation of hypertension-induced TMA is indistinguishable from TTP-induced TMA, except for the presence of severe hypertension. However, a history of hypertension, significant renal impairment, relatively modest thrombocytopenia, and lack of a severe ADAMTS-13 (a disintegrin and metalloprotease with thrombospondin type 1 motif 13 ) deficiency (activity > 10\% in hypertension-induced TMA) serve as useful clues for diagnosis of hypertension-induced TMA [3]. We report a case of recurrent TMA caused by a hypertensive urgency in a patient with end-stage renal disease (ESRD).

\section{Case Presentation}

A 26-year-old African American male with a past medical history of hypertension, end-stage renal disease managed by hemodialysis presented to the emergency department with complaints of abdominal pain, nausea, and vomiting. He had been noncompliant with his antihypertensive medications which included nifedipine, hydralazine, and spironolactone. On presentation, the patient's blood pressure was 231/123 $\mathrm{mmHg}$. Laboratory workup showed a white blood count of $17.3 \times 109 / \mathrm{L}$ (normal range: 4.5 to $11.0 \times 109 / \mathrm{L}$ ), hemoglobin $7.8 \mathrm{gm} / \mathrm{dL}$ (normal range: 13.5 to $17.5 \mathrm{~g} / \mathrm{dL}$ ), platelet count $46 \times 109 / \mathrm{L}$ (normal range: $150-400 \times$ 109/L), reticulocyte count $7.8 \%$, total bilirubin $1 \mathrm{mg} / \mathrm{dL}$ (normal range: 0.1 to $1.2 \mathrm{mg} / \mathrm{dL}$ ), lactate dehydrogenase 1,235 U/L (normal range: 140 to $280 \mathrm{U} / \mathrm{L}$ ), haptoglobin < $10 \mathrm{mg} / \mathrm{dL}$, and direct Coomb's test was negative. Numerous schistocytes were identified on a peripheral blood smear (Figure 1). 


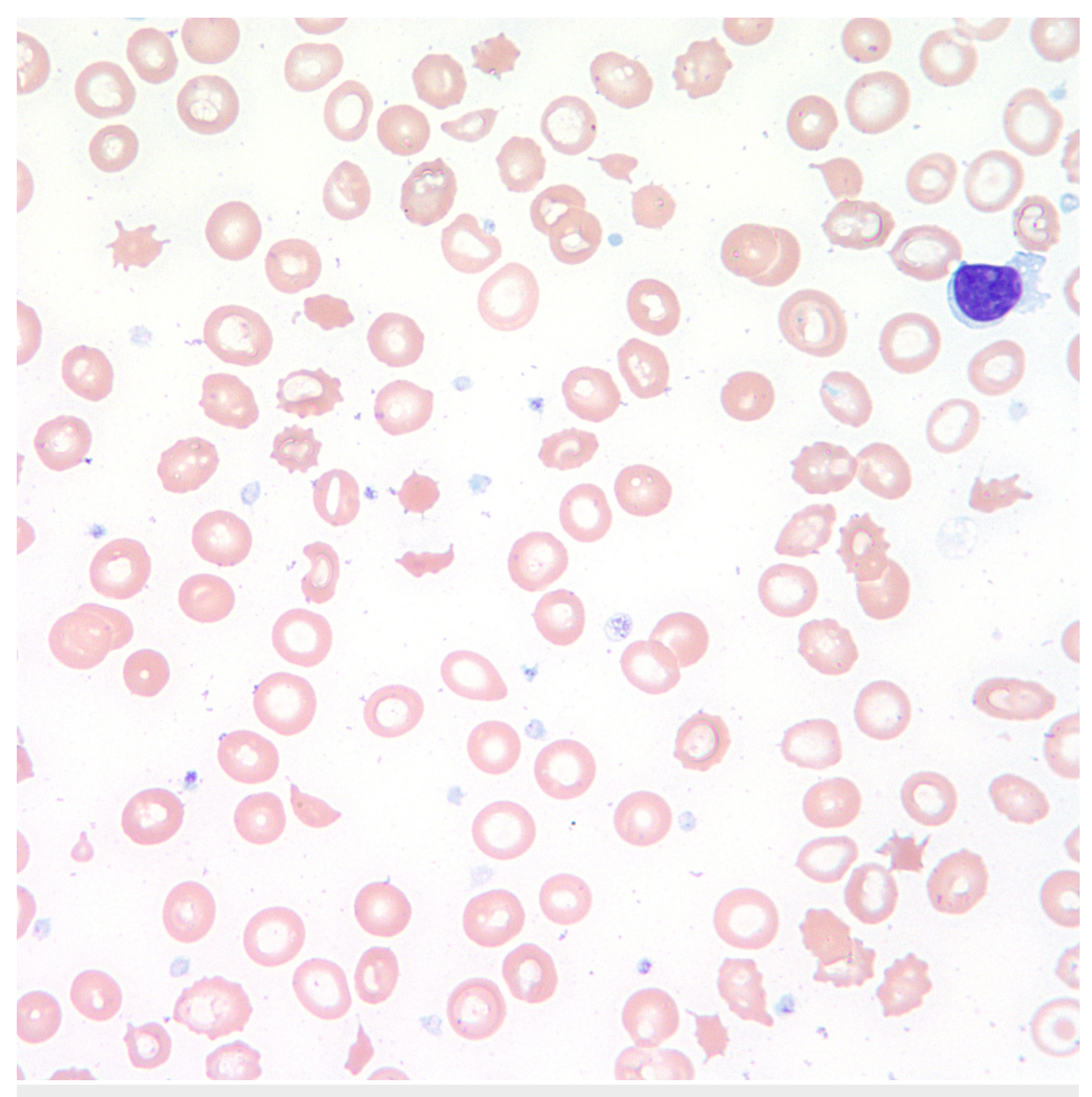

FIGURE 1: Peripheral blood smear showing schistocytes

\section{Discussion}

Hypertensive urgency can affect up to $1 \%$ of all hypertensive patients and accounts for $3 \%$ of all emergency room visits and $25 \%$ of all medical emergencies [4-5]. Although malignant hypertension is a common reason for patients to visit the emergency department, it rarely causes TMA. In malignant hypertension, the autoregulatory mechanisms controlling blood pressure fails. This results in damage to the vascular endothelium and obliteration of the vascular lumen which leads to fibrin clots and platelets clots within the microvascular network and subsequently causes hemolysis of red blood cells and platelet consumption in this process [6].

The initial clinical presentation of hypertension-induced TMA is indistinguishable from TTP-induced TMA, except for the presence of severe hypertension. TTP is characterized by the presence of unexplained microangiopathic hemolytic anemia, thrombocytopenia, fever, acute renal impairment, and neurological deficits, although this pentad is rare (present in $<5 \%$ cases).

TTP is a disorder of von Willebrand factor (VWF) proteolysis, which is caused by either a congenital deficiency or an autoimmune-acquired, antibody-mediated destruction of plasma metalloprotease, ADAMTS-13. VWF and platelets have the tendency to form aggregates in high shear stress in the microcirculation that is mitigated by ADAMTS-13. In absence of ADAMTS 13 activity, VWF-platelets aggregate and form microvascular thrombosis of TTP. Documenting severe ADAMTS-13 deficiency (activity $<10 \%$ ) supports the diagnosis of TTP [7]. However, TTP is a clinical diagnosis and measurement of ADAMTS-13 activity is not required to initiate initial management with plasmapheresis as it is a medical emergency with a very high mortality rate if left untreated. Therefore, it is important to diagnose TTP promptly in appropriate clinical settings and treat accordingly. However, a history of hypertension, significant renal impairment, relatively modest thrombocytopenia, and a lack of severe ADAMTS-13 deficiency (activity > 10\% in hypertension-induced TMA) serve as useful clues for the diagnosis of hypertension-induced TMA. Also, fever is uncommon in patients with TMA caused by malignant hypertension. Common presenting symptoms in these patients can be headache, blurry vision, dizziness, nausea, vomiting, and abdominal pain, as was the case in our patient [3].

Inability to reliably differentiate TTP from malignant hypertension-induced TMA clinically presents as a 


\section{Conclusions}

TMA is a clinical syndrome that is characterized by microangiopathic hemolytic anemia, thrombocytopenia, and organ injury. Severe hypertension can induce thrombotic microangiopathy, mimicking that induced by TTP. Plasma exchange is not utilized for management of hypertension-induced thrombotic microangiopathy; instead, blood pressure control is the treatment of choice. The absence of fever, modest thrombocytopenia, and elevated blood pressure favors the diagnosis of hypertension-induced TMA in comparison with TTP.

\section{Additional Information}

\section{Disclosures}

Human subjects: Consent was obtained by all participants in this study. Conflicts of interest: In compliance with the ICMJE uniform disclosure form, all authors declare the following: Payment/services info: All authors have declared that no financial support was received from any organization for the submitted work. Financial relationships: All authors have declared that they have no financial relationships at present or within the previous three years with any organizations that might have an interest in the submitted work. Other relationships: All authors have declared that there are no other relationships or activities that could appear to have influenced the submitted work.

\section{References}

1. George JN, Nester CM: Syndromes of thrombotic microangiopathy. N Engl J Med. 2014, 371:654-66. 10.1056/NEJMra1312353

2. George JN, Charania RS: Evaluation of patients with microangiopathic hemolytic anemia and thrombocytopenia. Semin Thromb Hemost. 2013, 39:153-60. 10.1055/s-0032-1333538

3. Khanal N, Dahal S, Upadhyay S, et al.: Differentiating malignant hypertension-induced thrombotic microangiopathy from thrombotic thrombocytopenic purpura. Ther Adv Hematol. 2015, 6:97-102. 10.1177/2040620715571076

4. Aggarwal M, Khan IA: Hypertensive crisis: hypertensive emergencies and urgencies. Cardiol Clin. 2006, 24:135-46.

5. Zampaglione B, Pascale C, Marchisio M, Cavallo-Perin P: Hypertensive urgencies and emergencies. Prevalence and clinical presentation. Hypertension. 1996, 27:144-47.

6. Strandgaard S, Paulson OB: Cerebral blood flow and its pathophysiology in hypertension. Am J Hypertens. 1989, 2:486-92. 10.1093/ajh/2.6.486

7. Sarode R, Bandarenko N, Brecher ME, et al.: Thrombotic thrombocytopenic purpura: 2012 American Society for Apheresis (ASFA) consensus conference on classification, diagnosis, management, and future research. J Clin Apher. 2014, 29:148-67. 10.1002/jca.21302 